\title{
Аналитическая геометрия кристаллической горной породы
}

\author{
Войтеховский Ю.Л. ${ }^{1,2}$, Захарова А.А. ${ }^{2}$ \\ ${ }^{1}$ Геологический институт ФИЦ КНЦ РАН, Anamumbl,woyt@geoksc.apatity.ru \\ ${ }^{2}$ Санкт-Петербургский горный университет, Санкт-Петербург
}

Аннотация. Статья развивает метод структурной индикатрисы для типизации петрографических структур. Предложено алгебраическое уравнение состояния горной породы с коэффициентами - вероятностями тернарных межзерновых контактов. На примере биминеральных кристаллических горных пород установлен изоморфизм типовых петрографических структур и кривых 3-го порядка, связанных непрерывными и дискретными переходами. Показано, что важной классификационной границей служит равновесие ХардиВайнберга, соотносимое с массивными текстурами.

Ключевые слова: кристаллическая горная порода, петрографическая структура, уравнение состояния, структурная индикатриса, равновесие Харди-Вайнберга.

\section{Analytical geometry of crystalline rock}

Voytekhovsky Y.L. ${ }^{1,2}$, Zakharova A.A. ${ }^{2}$

${ }^{1}$ Geological Institute of FRC KSC RAS, Apatity,woyt@geoksc.apatity.ru

${ }_{2}^{2}$ Saint Petersburg Mining University, Saint Petersburg

Abstract. The article develops the structural indicatrix method for typing petrographic structures. An algebraic equation of state of a rock with coefficients - probabilities of ternary intergrain contacts is proposed. On the example of bimineral crystalline rocks, the isomorphism of typical petrographic structures and curves of the $3^{\text {rd }}$ order, connected by continuous and discrete transitions, has been established. It is shown that the Hardy-Weinberg equilibrium correlated with massive textures serves as an important classification boundary.

Key words: crystalline rock, petrographic structure, equation of state, structural indicatrix, Hardy-Weinberg equilibrium.

Структура и текстура - неотъемлемые атрибуты горной породы (Петрографический словарь, 1981), обязательные при ее стандартном описании (Петрографический кодекс..., 2008). Первая характеризует отношения минеральных зерен, вторая - их разного вида кластеров. Редкие авторы задаются вопросом, всегда ли можно разделить эти категории (Штейнберг, 1957). Генетическая интерпретация структур состоит в сравнительном анализе степени идиоморфизма минеральных индивидов различных видов, текстур - в выделении их парагенетических ассоциаций (Бетехтин и др., $1958,1964)$. Современная описательная систематика насчитывает их неопределенное число порядка несколько сотен (Шахов, 1961; Исаенко, 1964; Половинкина, 1966). При этом в стороне остаются фундаментальные вопросы о горной породе как системе со строго определенными элементами и отношениями и возможности единого описания всего многообразия структур и текстур.

Авторы рассматривают кристаллическую горную породу как связный агрегат неопределенно большого числа минеральных индивидов в общем случае различных видов. В соответствии с общей теорией систем, при данном составе их структуры в первую очередь определяются разнообразием межэлементных отношений, во вторую - их интенсивностями. То есть, при фиксированном модальном составе горной породы специфика рисунка межзерновых границ, схватываемая термином структура, в первую очередь определяется статистикой межзерновых контактов, во вторую - их метрикой. В этом - принципиальное отличие от подхода, разделяющего систему межзерновых границ на фрагменты, идиоморфные или ксеноморфные для контактирующих индивидов.

Топология межзерновых границ редко обсуждается в петрографии (Вернон, 1980), гораздо чаще - в металлургии (Салтыков, 1958; Беленький, 1980). Между тем, здесь есть строгие закономерности. В горных породах, металлах и сплавах есть бинарные (по поверхностям), тернарные (тройные по ребрам) и куотернарные (четверные в точках) межзерновые контакты, статистики которых 
связаны определенными соотношениями. Очевидна и генетическая подоплека - все границы суть дефекты кристаллических структур, зоны обрыва химических связей, каналы свободной энергии. После установления физико-химического равновесия в горной породе наступает период дополнительной минимизации свободной энергии межзерновых границ. Результат особенно заметен в мономинеральных горных породах (мраморах, кварцитах), фирновом льде, керамике, отожженных металлах и сплавах. В них реализуется «структура Коксетера» сухой пены вопреки требованиям кристаллических решеток (Жабин, 1979, с. 45-76).
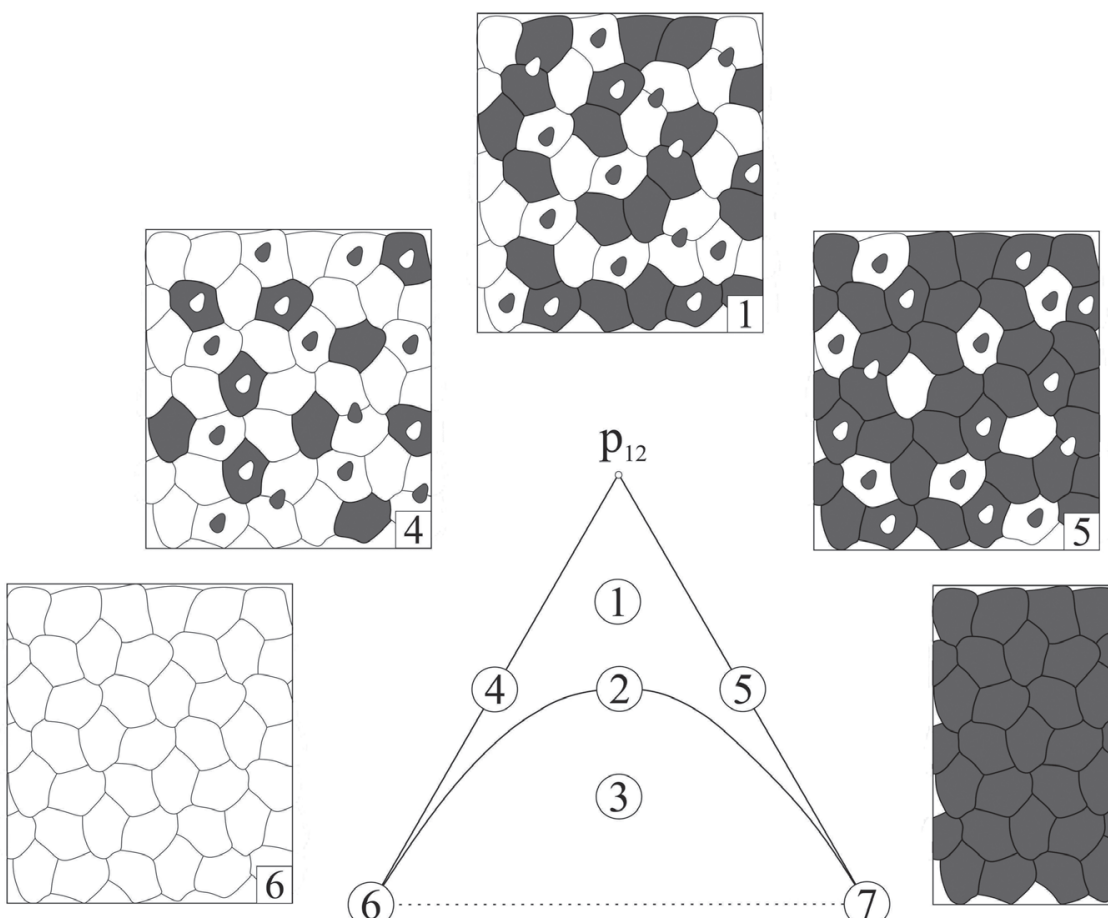

$\mathrm{p}_{11}$

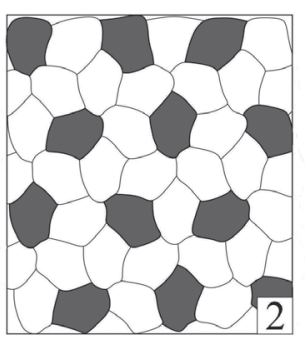

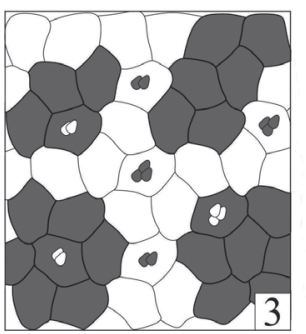

Рис. 1. Барицентрический треугольник вероятностей $\left\{\mathrm{p}_{11}, \mathrm{p}_{12}, \mathrm{p}_{22}\right\}$, линия равновесия Харди-Вайнберга и типовые петрографические структуры. Состояния $\mathrm{p}_{12}=1$ и $\mathrm{p}_{11}+\mathrm{p}_{22}=1$ (пунктирное ребро без вершин) невозможны.

Fig. 1. Barycentric triangle of probabilities $\left\{\mathrm{p}_{11}, \mathrm{p}_{12}, \mathrm{p}_{22}\right\}$, Hardy-Weinberg equilibrium line and typical petrographic structures. States $\mathrm{p}_{12}=1$ and $\mathrm{p}_{11}+\mathrm{p}_{22}=1$ (dotted edge without vertices) are impossible.

Организация горной породы (система межзерновых границ) в самом общем виде представима как многозначный автоморфизм (отображение в себя) множества минеральных видов, реализованных в слагающих ее минеральных индивидах:

$$
\left\{m_{i}\right\}_{1}^{n} \stackrel{\mathrm{P}_{i j}}{\longrightarrow}\left\{m_{i}\right\}_{1}^{n}
$$


Профессор Д.П. Григорьев не уставал повторять, что понятие «минерал» подразумевает сразу два смысла: «минеральный вид» и «минеральный индивид», различаемые из контекста. Указанный автоморфизм как раз и определяет их диалектику.

Статистика бинарных межзерновых контактов представима в виде уравнения состояния горной породы $\Sigma_{i} \Sigma_{j} p_{i j} m_{i} m_{j}=1$, где $i, j=1, \ldots, n$, произведение $m_{i} m_{j}$ имеет смысл контакта минералов $m_{i}$ и $m_{j}$, вероятности $p_{i j}-$ коэффициенты квадратичной формы. Матричная запись уравнения выявляет ведущую роль симметрической матрицы $\mathrm{P}_{i j}$ :

$$
\left[\begin{array}{llll}
m_{1} & m_{2} & \cdots & m_{n}
\end{array}\right]\left[\begin{array}{cccc}
p_{11} & p_{12} & \cdots & p_{1 n} \\
p_{21} & p_{22} & \cdots & p_{2 n} \\
\cdots & \cdots & \cdots & \cdots \\
p_{n 1} & p_{n 2} & \cdots & p_{m n}
\end{array}\right]\left[\begin{array}{c}
m_{1} \\
m_{2} \\
\cdots \\
m_{n}
\end{array}\right]=\mathrm{E}
$$

В статьях (Войтеховский, 1995, 2000) формальным выражением петрографической структуры определена каноническая диагональная форма матрицы $\mathrm{P}_{i j}$ (Ефимов, 1963; Боревич, 1988). Доказана теорема: в силу условия $p_{i j} \geq 0$ для n-минеральных горных пород возможны $\mathrm{n}$ типовых структур $\mathrm{S}_{\mathrm{n}}^{\mathrm{m}}$, где $\mathrm{m}=1, \ldots, \mathrm{n}$ - число положительных элементов в канонической диагональной форме матрицы $\mathrm{P}_{i j}$ Квадратичная поверхность, задаваемая уравнением состояния, названа структурной индикатрисой горной породы. Для биминеральных горных пород ситуация показана в барицентрическом треугольнике $\left\{\mathrm{p}_{11}, \mathrm{p}_{12}, \mathrm{p}_{22}\right\}$ (рис. 1,2 ). Разделительной границей двух возможных типов здесь служит равновесие Харди-Вайнберга (Стюарт, 1980) $\mathrm{p}_{11}=\mathrm{p}_{1}{ }^{2}, \mathrm{p}_{12}=2 \mathrm{p}_{1} \mathrm{p}_{2}, \mathrm{p}_{22}=\mathrm{p}_{2}{ }^{2}$, выражающее идеальное перемешивание минеральных зерен при любом модальном составе $\left\{\mathrm{p}_{1}, \mathrm{p}_{2}\right\}$ горной породы

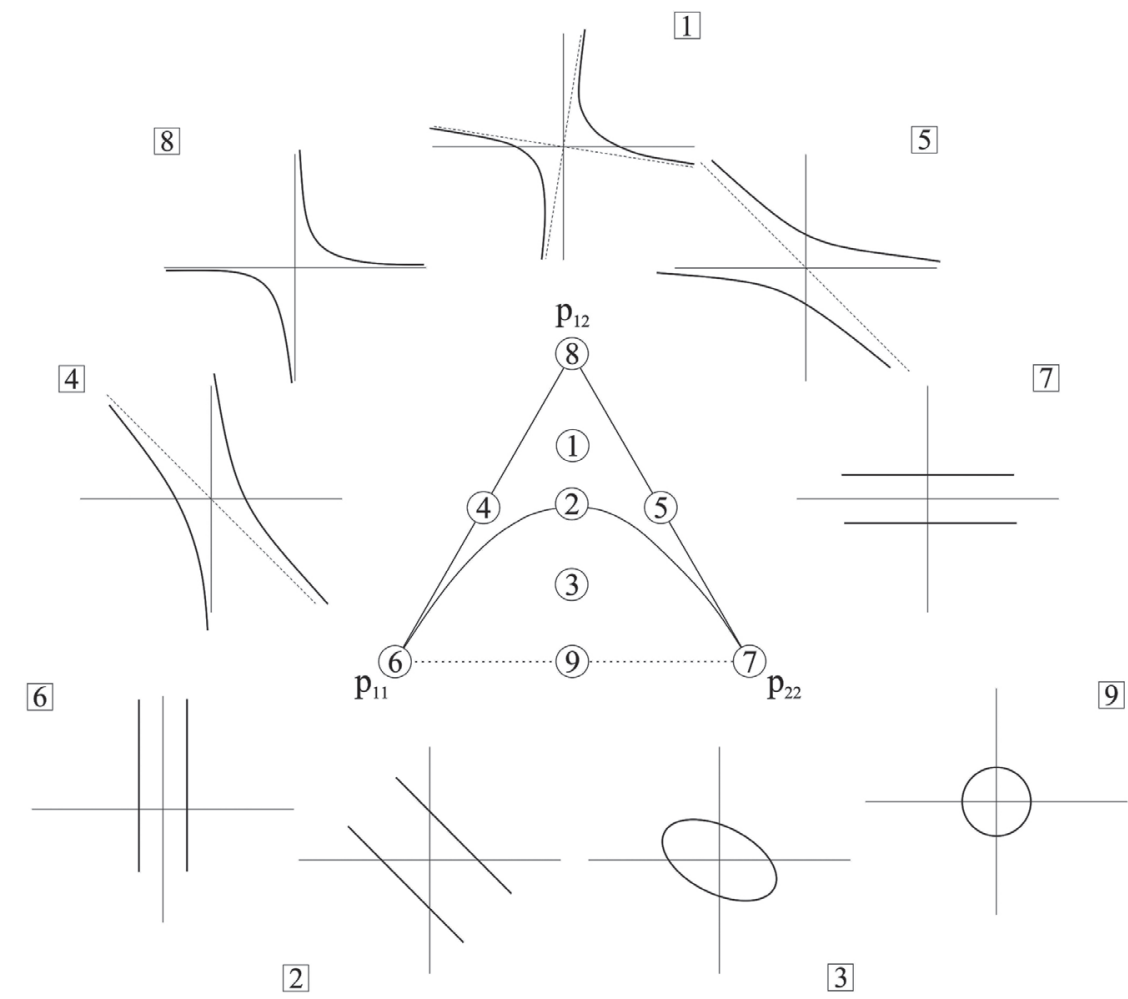

Рис. 2. Барицентрический треугольник вероятностей $\left\{\mathrm{p}_{11}, \mathrm{p}_{12}, \mathrm{p}_{22}\right\}$ и структурные индикатрисы. Номера соответствуют рис. 1.

Fig. 2. Barycentric triangle of probabilities $\left\{\mathrm{p}_{11}, \mathrm{p}_{12}, \mathrm{p}_{22}\right\}$ and structural indicatrices. The numbers correspond to fig. 1 . 
(гомогенные структуры) и, вероятно, отвечающее массивной текстуре. Структура, как она определена выше - инвариант организации горной породы, вариабельной в пределах поля диаграммы. Переход через границу Харди-Вайнберга меняет ее качественно.

Для тех же биминеральных горных пород уравнение состояния $\Sigma_{i} \Sigma_{j} \Sigma_{k} p_{i j k} m_{i} m_{j} m_{k}=1$, где $i, j, k=1, \ldots, n$, произведение $m_{i} m_{j} m_{k}$ имеет смысл контакта минералов $m_{i} m_{j}$ и $m_{k}$, а вероятности $p_{i j k}$ - коэффициенты кубической формы, позволяет построить еще более фундаментальную (так как $p_{i j}$ вычисляемы по $\left.p_{i j k}\right)$ систематику структур. Барицентрический тетраэдр вероятностей $\left\{\mathrm{p}_{111}, \mathrm{p}_{112}, \mathrm{p}_{122}, \mathrm{p}_{222}\right\}$ с типовыми структурами и их индикатрисами 3-го порядка (Савелов, 2002) показан на рис. 3 и 4.

Таким образом, предложенное уравнение состояния позволяет охватить единым математическим формализмом огромное разнообразие кристаллических горных пород. На примере биминеральных горных пород показано, как структурные индикатрисы 2-го (для бинарных контактов) и 3-го (для тернарных контактов) порядков сохраняют топологический тип в определенных полях барицентрических диаграмм и изменяются скачком на естественных границах, не зависящих от произвола исследователя.
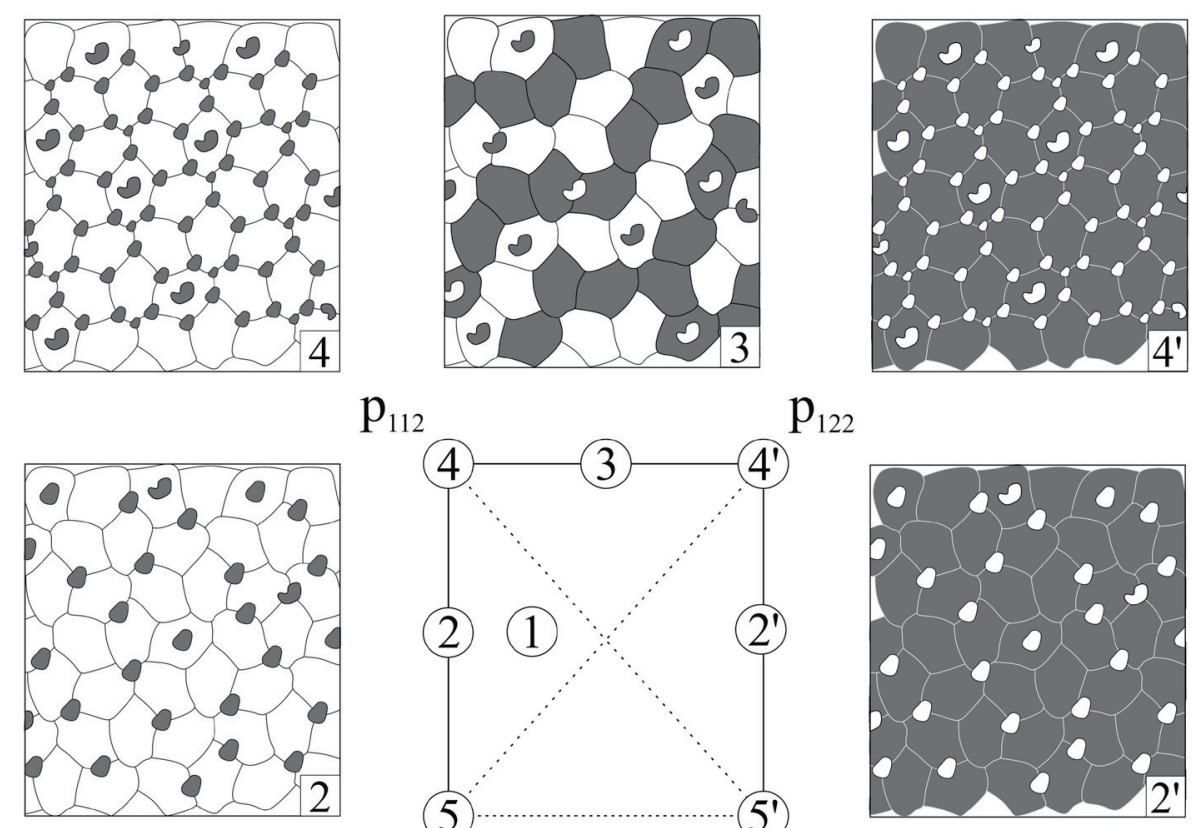

$\mathrm{p}_{112}$

$\mathrm{p}_{122}$
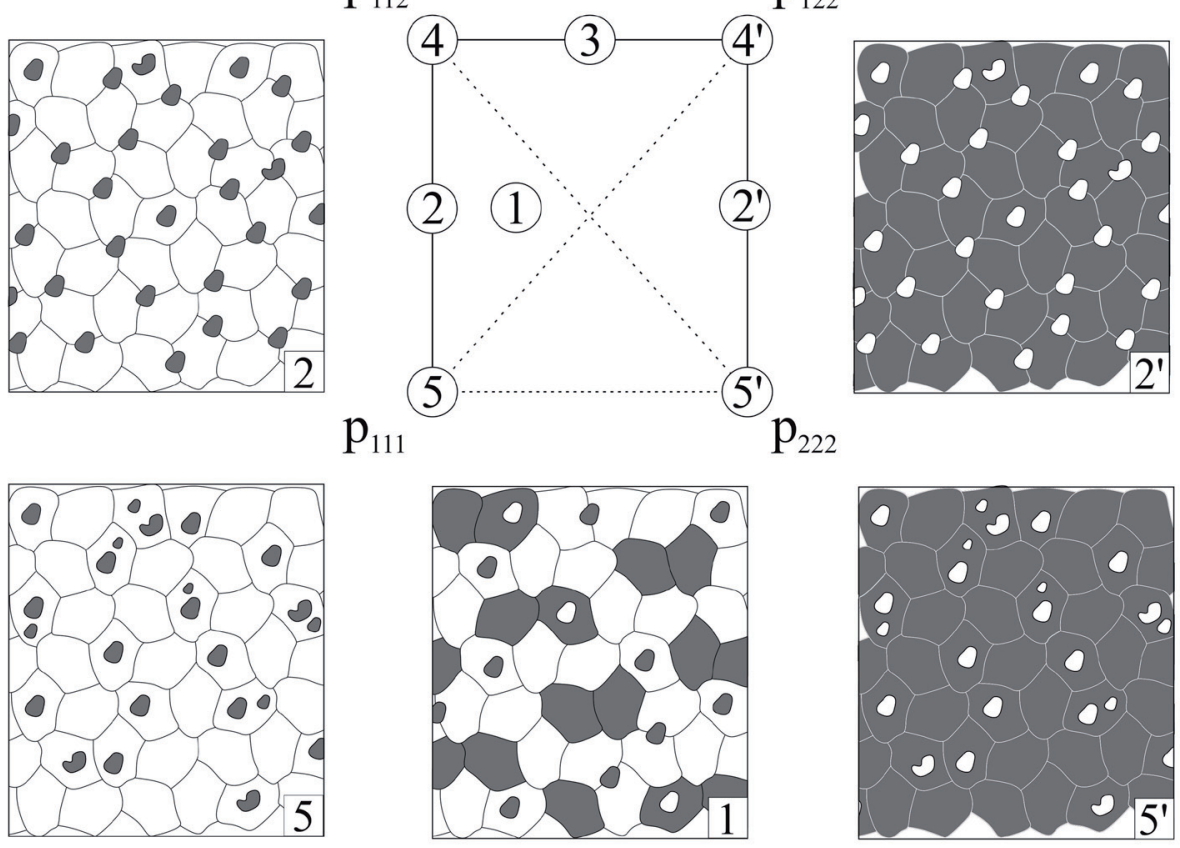

Рис. 3. Барицентрический тетраэдр вероятностей $\left\{\mathrm{p}_{111}, \mathrm{p}_{112}, \mathrm{p}_{122}, \mathrm{p}_{222}\right\}$, линии равновесия Харди-Вайнберга и типовые петрографические структуры. Состояния $\mathrm{p}_{112}=0$ (без ребра $\mathrm{p}_{122}+\mathrm{p}_{222}=1$ ) и $\mathrm{p}_{122}=0$ (без ребра $\mathrm{p}_{112}+\mathrm{p}_{111}=1$ ) невозможны.

Fig. 3. Barycentric tetrahedron of probabilities $\left\{\mathrm{p}_{111}, \mathrm{p}_{112}, \mathrm{p}_{122}, \mathrm{p}_{222}\right\}$, Hardy-Weinberg equilibrium lines and typical petrographic structures. States $\mathrm{p}_{112}=0$ (without the edge $\mathrm{p}_{122}+\mathrm{p}_{222}=1$ ) and $\mathrm{p}_{122}=0$ (without the edge $\mathrm{p}_{112}+\mathrm{p}_{111}=1$ ) are impossible. 

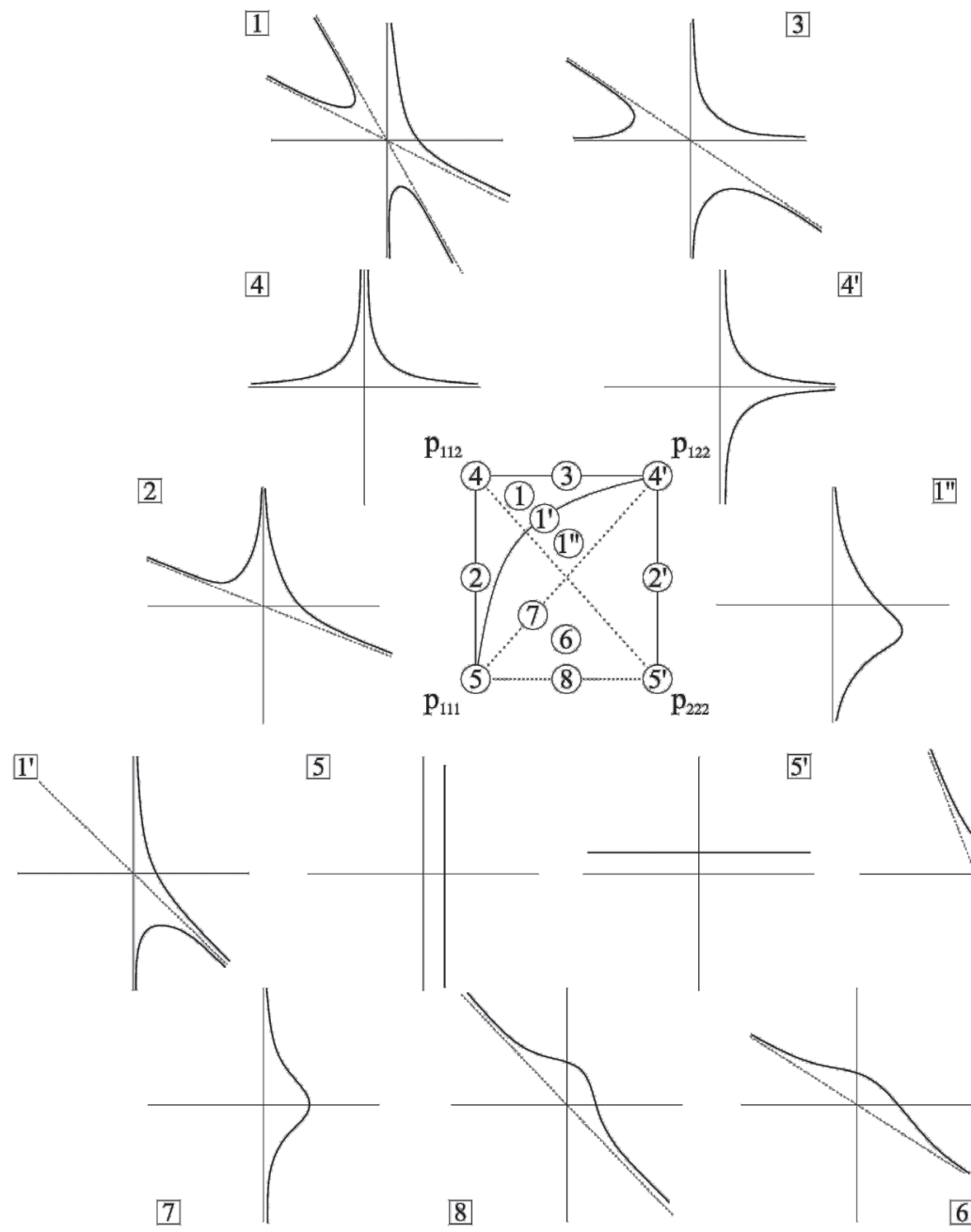

5
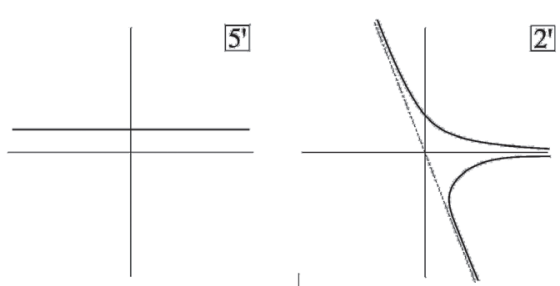

7

8

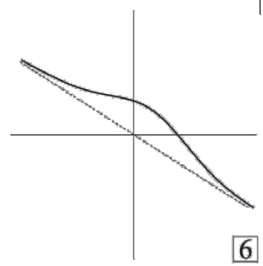

Рис. 4. Барицентрический тетраэдр вероятностей $\left\{\mathrm{p}_{111}, \mathrm{p}_{112}, \mathrm{p}_{122}, \mathrm{p}_{222}\right\}$ и структурные индикатрисы. Номера соответствуют рис. 3 .

Fig. 4. Barycentric tetrahedron of probabilities $\left\{\mathrm{p}_{111}, \mathrm{p}_{112}, \mathrm{p}_{122}, \mathrm{p}_{222}\right\}$ and structural indicatrices. The numbers correspond to fig. 3 .

Важная граница - равновесие Харди-Вайнберга, по-видимому, отвечающее массивным текстурам при любых модальных составах горных пород. Строго говоря, любая массивная текстура является структурой, так как выраженные кластеры в ней отсутствуют. Парадоксальность ситуации состоит еще и в том, что указанное равновесие никогда не реализуется - фигуративная точка горной породы может попасть в поле диаграммы, но не на границу. Отнесение некоторой структуры к массивной текстуре - статистическая задача, решаемая на основе критериев согласия.

Соотношение структур и текстур еще сложнее. Так, при условии $\mathrm{p}_{112} \approx \mathrm{p}_{122} \approx 1 / 2$ пространство биминеральной горной породы неизбежно организуется как система мономинеральных цепочек, то есть как текстура в современном понимании термина. Дальнейшая задача исследования - определение структурных индикатрис и естественных классификационных границ внутри барицентрического тетраэдра $\left\{\mathrm{p}_{111}, \mathrm{p}_{112}, \mathrm{p}_{122}, \mathrm{p}_{222}\right\}$ и переход к структурам триминеральных горных пород.

По крайней мере для кристаллических горных пород, в которых корректно определены элементы (минеральные зерна) и отношения (межзерновые контакты), можно развивать структурную теорию, последовательно добавляя метрику (протяженности, площади) и физическую характеристику (удельную свободную энергию) межзерновых границ. Должны ли петрографические струк- 
туры изначально иметь генетический подтекст, тем более закрепленный в номенклатуре (грано-, лепидо-, немато-, порфиро-, пойкило-, гомео-, гетеро- и др. бластовые структуры) - вопрос дискуссионный. Но заметим, что структурная кристаллография совершенно агенетична, что и позволяет ей - через посредство кристаллохимии, шаг за шагом, с множеством оговорок насыщающей заведомо математические конструкции физико-химическими интерпретациями - быть надежной основой генетической минералогии.

\section{Литература}

1. Беленький В.3. Геометрико-вероятностные модели кристаллизации. Феноменологический подход. М. Изд-во: Наука. 1980. 88 с.

2. Бетехтин А.Г., Генкин А.Д., Филимонова А.А., Шадлун Т.Н. Текстуры и структуры руд. М. Изд-во: Госгеолтехиздат, 1958. $436 \mathrm{c}$.

3. Бетехтин А.Г., Генкин А.Д., Филимонова А.А., Шадлун Т.Н. Структурно-текстурные особенности эндогенных руд. М. Изд-во: Недра. 1964. 598 с.

4. Боревич 3.И. Определители и матрицы. М. Изд-во: Наука. 1988. 184 с.

5. Вернон Р.Х. Метаморфические процессы. М. Изд-во: Недра. 1980. 228 с.

6. Войтеховский Ю.Л. Приложение теории квадратичных форм к проблеме классификации структур полиминеральных горных пород // Изв. ВУЗов. Геол. и разведка. 1995. № 1. С. 32-42.

7. Войтеховский Ю.Л. Количественный анализ петрографических структур: метод структурной индикатрисы и метод вычитания акцессориев // Изв. вузов. Геол. и разведка. 2000. № 1. С. 50-54.

8. Ефимов Н.В. Квадратичные формы и матрицы. М. Изд-во: Физматгиз. 1963. 160 с.

9. Жабин А.Г. Онтогения минералов. Агрегаты. М. Изд-во: Наука. 1979. 276 с.

10. Исаенко М.П. Определитель структур и текстур руд. М. Изд-во: Недра. 1964. 156 с.

11. Петрографический кодекс России. Магматические, метаморфические, метасоматические, импактные образования. СПб. Изд-во: ВСЕГЕИ. 2008. 200 с.

12. Петрографический словарь / Ред. В.П. Петров и др. М. Изд-во: Недра. 1981. 496 с.

13. Половинкина Ю.Ир. Структуры и текстуры изверженных и метаморфических горных пород. М. Издво: Недра. 1966. Ч. 1. 240 с.; Ч. 2. Т. 1. 424 с.; Ч. 2. Т. 2. 272 с.

14. Савелов А.А. Классификация Ньютона. Плоские кривые: систематика, свойства, применения. МоскваИжевск: НИЦ «Регулярная и хаотическая динамика». 2002. С. 44-53.

15. Салтыков С.А. Стереометрическая металлография. М. Изд-во: Металлургия. 1958. 446 с.

16. Стюарт Я. Концепции современной математики. Мн.: Вышэйшая школа. 1980. 382 c.

17. Шахов Ф.Н. Текстуры руд. М. Изд-во: АН СССР. 1961. 180 с.

18. Штейнберг Д.С. Структуры горных пород. Свердловск. Изд-во: СГИ. 1957. 72 с. 